\title{
Antioxidant activity of extracts from Calocedrus formosana leaf, bark, and heartwood
}

\begin{abstract}
Calocedrus formosana Florin (Cupressaceae) is an endemic tree to Taiwan. To evaluate the antioxidant activity of the plant extracts from heartwood, bark, and leaf of C. formosana, assays for 1,1-diphenyl-2-picrylhydrazyl (DPPH) radical and superoxide anion scavenging activities, as well as prevention of DNA strand cleavage were performed in this study. Similar $\mathrm{IC}_{50}$ values against the $\mathrm{DPPH}$ radical were found for the heartwood and bark extracts at approximately $23 \mu \mathrm{g} / \mathrm{ml}$. Moreover, the heartwood extract exhibited the highest inhibitory activity against superoxide radicals among the test samples; a 2.3-fold lower value of $\mathrm{IC}_{50}$ for superoxide radical inhibition was found in the heartwood extract relative to that of $(+)$-catechin. Much less effect on inhibition of DPPH and superoxide radicals was found from the leaf extract of $C$. formosana. More than $70 \%$ of superoxide radicals were inhibited in the presence of $10 \mu \mathrm{g} / \mathrm{ml}$ heartwood extract, whereas only $15 \%$ inhibition was obtained from the leaf extract. The heartwood extract, at a dose of approximately $0.5 \mathrm{mg} / \mathrm{ml}$, apparently completely prevented the $\Phi \mathrm{X} 174$ supercoiled DNA cleavage induced by ultraviolet photolysis of $\mathrm{H}_{2} \mathrm{O}_{2}$, as judged by agarose gel electrophoresis. This report also suggests that the antioxidant activities of the plant extracts of C. formosana are in good correlation with their phenolic contents.
\end{abstract}

Key words Calocedrus formosana . Heartwood extract . Antioxidant activity $\cdot$ Total phenolic content

S.-T. Chang $(\bowtie) \cdot$ J.-H. Wu $\cdot$ S.-S. Cheng

Department of Forestry, National Taiwan University, No. 1 Section 4

Roosevelt Road, Taipei 106, Taiwan

Tel. +886-2-23630231-3196; Fax +886-2-23654520

e-mail: peter@ntu.edu.tw

L.-F. Shyur · S.-Y. Wang · C.-P. Lo · H.-N. Chang

Institute of BioAgricultural Sciences, Academia Sinica, Taipei 115,

Taiwan

Tel. +886-2-27899322; Fax +886-2-27899322

e-mail: lfshyur@ccvax.sinica.edu.tw

\section{Introduction}

Secondary metabolites of trees commonly play important roles in specific chemical or physical properties of the wood, such as color, odor, durability, and others. Furthermore, many natural compounds isolated from woody plants have been found to have significant pharmacological activities, with great potential for further development as drugs or drug analogs for human disease control. Taxol and podophyllotoxin isolated from conifers are two typical and well-known examples, which have been recognized as potent antitumor drugs. Reactive oxygen species (ROS), e.g., superoxide radicals, hydroxyl radicals, and hydrogen peroxide, have been proposed as significant causative factors in some radical-mediated conditions including aging, ${ }^{1}$ cancer ${ }^{2,3}$ and cardiovascular disease. ${ }^{4}$ The search for potent natural antioxidants, especially from plant sources, as nutritional supplements, health food, and/or phytomedicine has become an important research issue at a world-wide level. Many physicians and researchers now contemplate the use of antioxidant treatments as a key strategy for inhibiting or reversing the process of carcinogenesis. ${ }^{5}$

Calocedrus formosana Florin (Cupressaceae) is an endemic tree that grows at elevations of $800-1500 \mathrm{~m}$ in Taiwan's central mountains. The physico-chemical properties of the timbers of this plant are well recognized for their decay resistance and excellent durability. With regard to the phytochemical studies of $C$. formosana, more than $30 \mathrm{com}$ pounds have been isolated from the plant including monoterpenes, diterpenes, lignans, and steroids. ${ }^{6-10}$ Recently, we identified that the major compound of the exudates from the bark surface of $C$. formosana is ferruginol. ${ }^{11}$ However, we have found nothing regarding the potential human health benefits of the extracts and phytocompounds of this plant. In our recent studies on Taiwania cryptomerioides (Taxodiaceae), another indigenous conifer tree species grown in Taiwan, we identified several forms of diterpenes from its heartwood, and found that ferruginol exhibited the most significant antioxidant activity among the diterpenes. ${ }^{12}$ Based on the characteristics of the compounds isolated 
from $C$. formosana and to explore the additional utilization value of extractives from $C$. formosana, we found it of interest to investigate the antioxidant activity of this plant.

In this study a number of in vitro assays including 1,1-diphenyl-2-picrylhydrazyl (DPPH) radical scavenging activity test, nitroblue tetrazolium chloride (NBT) assay, and hydroxyl radical-induced DNA strand scission assay were performed to evaluate the antioxidant activities of $C$. formosana extracts. Several previous reports have demonstrated that phenolic compounds have multiple biological effects, especially for antioxidant activity. ${ }^{13}$ Therefore, we quantitatively analyzed the phenolics in C. formosana and compared their distributions in its various tissues. Our results demonstrated that the total ethanolic extract of heartwood contains the highest amount of phenolic compounds, and that it also exhibited the most significant antioxidant activity among the tested extracts. Moreover, the inhibition of heartwood extract for ROS is comparable to that of $(+)$ catechin, which is well known for potential antioxidant activity. This report indicates that plant extracts or derived compounds from $C$. formosana may serve as good candidates for further development as nutraceutical or antioxidant remedies.

\section{Materials and methods}

\section{Preparation of plant extracts}

Leaf, bark and heartwood of Calocedrus formosana were collected from the experimental forest of National Taiwan University in central Taiwan. The dried samples were cut into small pieces and soaked in $70 \%(\mathrm{v} / \mathrm{v})$ ethanolic aqueous solution at room temperature for 7 days. The extract was decanted, filtered under vacuum, concentrated in a rotary evaporator, and then lyophilized. The resulting powder extracts were employed for the current study.

\section{Reagents}

1,1-Diphenyl-2-picrylhydrazyl (DPPH), hypoxanthine, xanthine oxidase, nitroblue tetrazolium chloride (NBT), $\Phi X 174$ RF1 supercoiled DNA, Folin-Ciocalteu's reagent, $(+)$-catechin, and gallic acid were purchased from Sigma (St. Louis, MO, USA). The other chemicals and solvents used in this study were of the highest quality available.

\section{DPPH assay}

Scavenging actions of DPPH free radical by $C$. formosana extracts were measured as follows. The reaction mixture contained $1000 \mu \mathrm{l}$ of $0.1 \mathrm{mM}$ DPPH-ethanol solution, $450 \mu \mathrm{l}$ of $0.05 \mathrm{M}$ Tris- $\mathrm{HCl}$ buffer ( $\mathrm{pH} 7.4$ ), and $50 \mu \mathrm{l}$ of test samples (final concentrations were $1,5,10,30$, and $50 \mu \mathrm{g} / \mathrm{ml}$, respectively) or methanol (control). Reduction of the DPPH free radical was measured by reading the absorbance at $517 \mathrm{~nm}$ exactly $30 \mathrm{~min}$ after adding each of the extracts. ${ }^{14}$
$(+)$-Catechin was used as a positive reference in this experiment. The inhibition ratio was expressed as a percentage after being calculated from the following equation: $\%$ Inhibition $=[($ absorbance of control - absorbance of test sample)/absorbance of control] $\times 100$.

\section{NBT (superoxide scavenging) assay}

Measurement of superoxide radical scavenging activity was carried out based on the method described by Kirby and Schmidt ${ }^{15}$ with slight modifications. Twenty microliters of $15 \mathrm{mM} \mathrm{Na}{ }_{2}$ EDTA in buffer ( $\left.50 \mathrm{mM} \mathrm{KH}_{2} \mathrm{PO}_{4} / \mathrm{KOH}, \mathrm{pH} 7.4\right)$, $50 \mu \mathrm{l}$ of $0.6 \mathrm{mM}$ NBT in buffer, $30 \mu \mathrm{l}$ of $3 \mathrm{mM}$ hypoxanthine in $50 \mathrm{mM} \mathrm{KOH}, 5 \mu \mathrm{l}$ of test samples in methanol (final concentrations were $1,5,10$, and $50 \mu \mathrm{g} / \mathrm{ml}$, respectively), and $145 \mu \mathrm{l}$ of buffer were mixed in 96-well microplates (Falcon, USA). The reaction was started by adding $50 \mu$ l of xanthine oxidase solution (1 unit in $10 \mathrm{ml}$ buffer) to the mixture, which was incubated at $25^{\circ} \mathrm{C}$. The absorbance at $570 \mathrm{~nm}$ was taken every $20 \mathrm{~s}$ up to $5 \mathrm{~min}$ using a plate reader (Labsystems Multiskan, Finland). The control contained $5 \mu \mathrm{l}$ methanol instead of the sample solution. (+)-Catechin was used as a positive reference. The inhibition ratio was expressed as a percentage after being calculated from the following equation: \% Inhibition $=[$ (rate of control - rate of sample reaction)/ rate of control] $\times 100$.

Inhibition of hydroxyl radical-induced DNA strand scission

The assay was done according to the method of Keum et al. ${ }^{16}$ with minor modifications. The reaction mixture $(30 \mu \mathrm{l})$ contained $10 \mathrm{mM}$ Tris- $\mathrm{HCl}$ in $1 \mathrm{mM}$ EDTA buffer ( $\mathrm{pH} 8.0)$, $\Phi$ X174 RF1 DNA $(0.3 \mu \mathrm{g})$, and $\mathrm{H}_{2} \mathrm{O}_{2}(0.04 \mathrm{M})$. Various amounts of the test extract samples dissolved in $10 \mu \mathrm{l}$ of ethanol (final concentrations of the plant extract in each assay were $1,10,100,500$, and $1000 \mu \mathrm{g} / \mathrm{ml}$, respectively) were added prior to the $\mathrm{H}_{2} \mathrm{O}_{2}$ addition. Hydroxyl radicals were generated by irradiation of the reaction mixtures at a distance of $5 \mathrm{~cm}$ with a 12-W ultraviolet (UV) lamp (Spectroline, Spectronics, USA). After incubation at room temperature for $20 \mathrm{~min}$, the reaction was terminated by the addition of a loading buffer $(0.25 \%$ bromophenol blue tracking dye and $40 \%$ sucrose), and the mixtures were then analyzed by $0.8 \%$ submarine agarose gel electrophoresis $(70 \mathrm{eV}, 1 \mathrm{~h})$. The gels were stained with ethidium bromide, destained in water, and photographed on a transilluminator.

\section{Determination of total phenolic content in plant extracts}

The phenolic contents in the plant extracts of $C$. formosana were measured according to the Folin-Ciocalteu method with slight modification. ${ }^{17}$ One milliliter of extract solution in methanol was mixed with an equal volume of $1 \mathrm{~N}$ FolinCiocalteu reagent and allowed to stand for $5 \mathrm{~min}$ at room temperature. After addition of $2.0 \mathrm{ml}$ of $20 \% \mathrm{Na}_{2} \mathrm{CO}_{3}$ and 
incubation at room temperature for another $10 \mathrm{~min}$, the mixture was centrifuged and the absorbance of the supernatant was measured at $730 \mathrm{~nm}$ on an UV/VIS spectrophotometer. The total phenolic content was expressed as gallic acid equivalents (GAE) in milligrams per gram dry material (plant extract).

\section{Statistical analyses}

All results were obtained from three independent experiments and expressed as mean $\pm \mathrm{SD}$. Analyses of variance were performed by ANOVA procedures. Significant differences $(P<0.05)$ were determined by Duncan's multiplerange test.

\section{Results}

Free radical scavenging activity of plant extracts from Calocedrus formosana

The free radical scavenging activities of Calocedrus formosana extracts were assessed by DPPH assay. As shown in Fig. 1, both bark and heartwood ethanolic extracts from $C$. formosana exhibited a significant inhibitory activity against the $\mathrm{DPPH}$ radical. Similar $\mathrm{IC}_{50}$ values for $\mathrm{DPPH}$ radical in bark and heartwood extracts were observed at approximately $23 \mu \mathrm{g} / \mathrm{ml}$. At $50 \mu \mathrm{g} / \mathrm{ml}$, two plant extracts inhibited more than $80 \%$ of the DPPH radical. Much less activity against the DPPH radical was found from leaf extract as compared with the bark and heartwood extracts (Fig. 1). The $\mathrm{IC}_{50}$ value of a well-known antioxidant compound, (+)-catechin, used as a reference in this study, is approximately $5 \mu \mathrm{g} / \mathrm{ml}$.

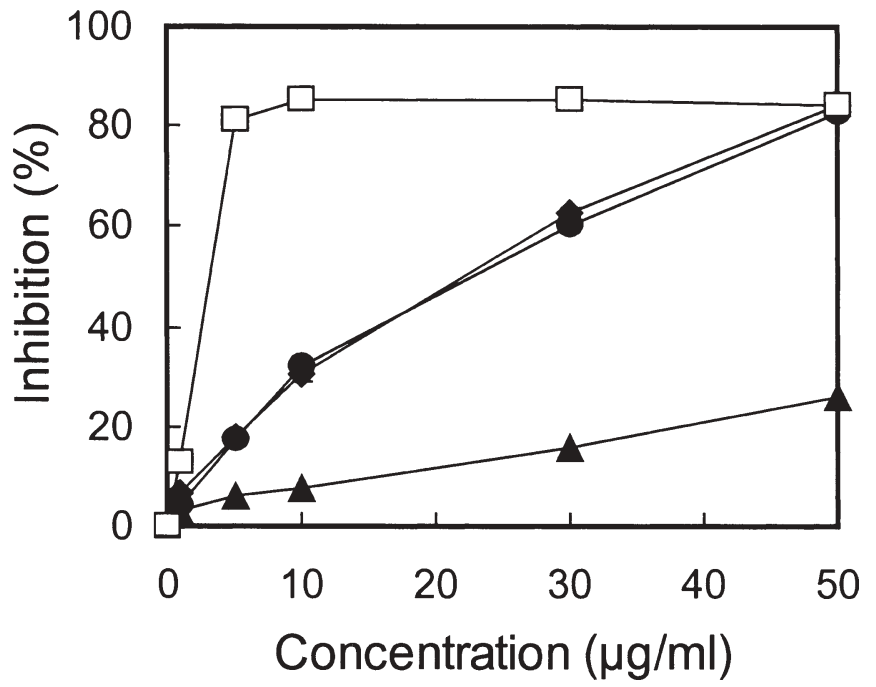

Fig. 1. Free-radical scavenging activity of plant extracts from Calocedrus formosana measured using the 1,1-diphenyl-2picrylhydrazyl (DPPH) assay. Results are mean \pm SD $(n=3)$. Diamonds, heartwood extract; circles, bark extract; triangles, leaf extract; squares, $(+)$-catechin
Superoxide scavenging activity of extracts from Calocedrus formosana

Figure 2 shows the superoxide scavenging activity of the C. formosana extracts and (+)-catechin. The heartwood extract shows a more inhibitory activity against superoxide radicals induced by hypoxanthine-xanthine oxidase than the bark and leaf extracts, as well as $(+)$-catechin at all tested concentrations. The $\mathrm{IC}_{50}$ values for $(+)$-catechin and the heartwood, bark, and leaf extracts of $C$. formosana were $7,3,4$, and $>50 \mu \mathrm{g} / \mathrm{ml}$, respectively (Fig. 2). Even with dosages as low as $10 \mu \mathrm{g} / \mathrm{ml}$, the heartwood extract was capable of scavenging more than $70 \%$ of the generated superoxide radicals in an assay, whereas bark extract, leaf extract, and $(+)$-catechin scavenged approximately $65 \%, 15 \%$, and $62 \%$, respectively. These results demonstrate that the ethanolic extracts of $C$. formosana heartwood show a better effect against superoxide radicals as compared with the well-known antioxidant $(+)$-catechin.

Inhibition of the hydroxyl radical-induced DNA strand scission

To further characterize the antioxidant bioactivity of the heartwood extract of $C$. formosana, an in vitro assay for determining the prevention of DNA strand cleavage induced by UV photolysis of $\mathrm{H}_{2} \mathrm{O}_{2}$ was performed in this study. Figure 3 shows that the heartwood extract effectively decreases the DNA strand scissions induced by hydroxyl radicals in a dosage-dependent manner. The native $\Phi \times 174$ RF1 DNA was shown with dominant supercoiled form DNA and there was little or no detectable change observed when the DNA was treated with $\mathrm{UV}$ or $\mathrm{H}_{2} \mathrm{O}_{2}$ alone, as judged by agarose gel electrophoresis (lanes 1-3).

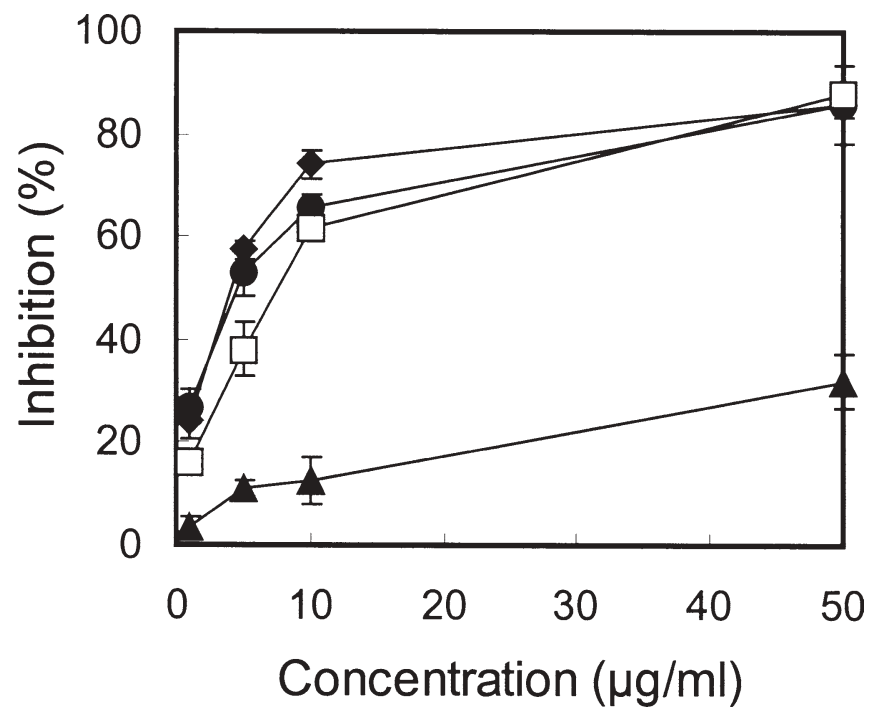

Fig. 2. Superoxide scavenging activity of $C$. formosana extracts measured using the nitroblue tetrazolium chloride (NBT) assay. Results are mean $\pm \mathrm{SD}(n=3)$. Diamonds, heartwood extract; circles, bark extract; triangles, leaf extract; squares, (+)-catechin 


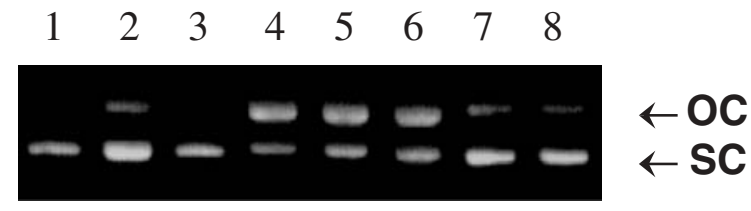

Fig. 3. Protection effect of heartwood extract of $C$. formosana on DNA strand scission induced by $\mathrm{H}_{2} \mathrm{O}_{2}$ and ultraviolet light (UV). Lane 1 represents native $\Phi \mathrm{X} 174$ DNA without any treatment. $\Phi \mathrm{X} 174 \mathrm{RF} 1$ supercoiled DNA was exposed to UV alone (lane 2), $\mathrm{H}_{2} \mathrm{O}_{2}$ alone (lane 3 ), UV plus $\mathrm{H}_{2} \mathrm{O}_{2}$ (lane 4). Lanes 5 to 8 represent supercoiled DNA that was incubated with $50,100,500$, and $1000 \mu \mathrm{g} / \mathrm{ml}$ of the heartwood extracts, respectively, and with $\mathrm{H}_{2} \mathrm{O}_{2}$ and UV illumination. DNA was analyzed by $0.8 \%$ agarose gel electrophoresis and visualized under the UV illuminator. Arrows indicate distinct forms of the bacteriophage DNA: $O C$, open circular; $S C$, supercoiled

Table 1. Total phenolic content of plant extracts from Calocedrus formosana

\begin{tabular}{lc}
\hline Extracts & Total phenolics $(\mathrm{mg} \text { of GAE/g) })^{\mathrm{a}}$ \\
\hline Heartwood & $159.5 \pm 1.9$ \\
Bark & $115.3 \pm 2.3$ \\
Leaf & $53.5 \pm 1.5$ \\
\hline
\end{tabular}

The experiments were measured by Folin-Ciocalteu method as described in detail under Materials and methods. Each experiment was performed in triplicate and the results are mean \pm SD. Values in the column are significantly different $(P<0.05)$

${ }^{a}$ Total phenolics are expressed as gallic acid equivalent (GAE)

Incubation of the supercoiled form of $\Phi X 174$ RF1 DNA with both $\mathrm{H}_{2} \mathrm{O}_{2}$ and UV resulted in significant conversion of the supercoiled DNA to open circular form (lane 4). The prevention of DNA strand scission was detected when the DNA was incubated with $50-100 \mu \mathrm{g} / \mathrm{ml}$ of heartwood extract (lanes 5 and 6). Strikingly, nearly complete protection by heartwood extract on the DNA scission was obtained at a dose of $500 \mu \mathrm{g} / \mathrm{ml}$ (lane 7).

\section{Total phenolics in the Calocedrus formosana extracts}

The content of total phenolics in the extracts of $C$. formosana was determined by using the Folin-Ciocalteu assay and was expressed as gallic acid equivalents (GAE). According to the results shown in Table 1, the total phenolic contents of the heartwood, bark, and leaf extracts were $159.5 \pm 1.9,115.3 \pm 2.3$, and $53.5 \pm 1.5 \mathrm{mg} / \mathrm{g}$, respectively. In other words, approximately 1.4 -fold and three-fold higher amounts of phenolics existed in the heartwood extract relative to that of the bark and leaf extracts, respectively.

\section{Discussion}

Various reactive oxygen species (ROS) encompass a spectrum of diverse chemical species including superoxide anions, hydrogen peroxide, hydroxyl radicals, nitric oxide, peroxynitrite, and others. These oxidants can play a variety of roles in both animals and plants in vivo. For instance, some of the ROS are involved in cellular signaling, cell growth regulation, specific cellular physiology, and energy production $;{ }^{18}$ however, the oxidation of lipids, DNA, protein, and carbohydrate by toxic ROS can also often cause DNA mutation, damage target cells or tissues, and result in cellular senescence and death. Recently, knowledge and application of potential antioxidant activities in reducing oxidative stresses in vivo have prompted many investigators to search for potent natural antioxidants from various plant sources. ${ }^{19-22}$ Calocedrus formosana, the target plant of this study, is an indigenous plant species of Taiwan, and little or no systematic study has been performed to address the specific bioactivities of this plant related to its potential pharmacological or nutritional usage. Thus, in this study, we characterized not only the antioxidant activities but also the protective effect on the DNA scission for the plant extracts of $C$. formosana.

Based on the results of DPPH-radical assay, the ethanolic extracts of both heartwood and bark of $C$. formosana exhibited a significant inhibitory activity against DPPH radical, whereas the leaf extract was found to have much less effect on free radical inhibition, as shown in Fig. 1. The superoxide radical is known to be produced in vivo and can result in the formation of $\mathrm{H}_{2} \mathrm{O}_{2}$ via dismutation reaction. Moreover, the conversion of superoxide and $\mathrm{H}_{2} \mathrm{O}_{2}$ into more reactive species, e.g., the hydroxyl radical, has been thought to be one of the unfavorable effects caused by superoxide radicals. ${ }^{18}$ Hence, in this report we have also evaluated the effect of $C$. formosana extracts on the inhibition of superoxide radicals. The data in Fig. 2 indicate that among the tested samples, the heartwood extract had the highest inhibitory activity against superoxide radicals induced by hypoxanthine-xanthin oxidase. Strikingly, the $\mathrm{IC}_{50}$ value against the superoxide radical in heartwood extract is 2.3 times lower than that of $(+)$-catechin, a well-known antioxidant. The leaf extract showed the lowest activity on superoxide radical inhibition.

Previous reports have demonstrated that the phenolic content in plants can be correlated to their antioxidant activities. ${ }^{17,23,24}$ In this study, the total phenolic content in the ethanol extracts of $C$. formosana was determined spectrometrically according to the Folin-Ciocalteu method and calculated as gallic acid equivalents (GAE), with the results as shown in Table 1. The total phenolic content of heartwood extract $(159.5 \pm 1.9 \mathrm{mg} / \mathrm{g})$ was higher than that of the bark extract $(115.3 \pm 2.3 \mathrm{mg} / \mathrm{g})$ and leaf extract $(53.5 \pm 1.5 \mathrm{mg} / \mathrm{g})$. These results suggest that the antioxidant activities of the heartwood, bark, and leaf extracts of $C$. formosana correlate well with their phenolic contents. In other words, the highest content of phenolics in heartwood extract has the most potent effect on antioxidant activity, relative to both bark and leaf extracts, as judged by the free radical and superoxide radical scavenging effects.

Hydroxyl radicals are considered to be the most active ROS, which can physically attack DNA to cause strand scission. Because the heartwood extract of $C$. formosana possessed the strongest antioxidant activity, we further characterized its protective activity on DNA strand scission. 
As the data in Fig. 3 show, heartwood extract, at a dose of $1 \mathrm{mg} / \mathrm{ml}$, virtually completely inhibited the $\Phi$ X174 RF1 DNA strand cleavage under oxidative stress of hydroxyl radical induced by UV photolysis of $\mathrm{H}_{2} \mathrm{O}_{2}$. Keum et al. ${ }^{16}$ have demonstrated that the methanolic extract of heat-processed ginseng can almost completely protect DNA from strand scission at a dose of $30 \mathrm{mg} / \mathrm{ml}$. In contrast, a dosage of 30-fold less was required for the heartwood extract of C. formosana to inhibit DNA damage, compared to the methanolic extract of heat-processed ginseng. This methanolic extract from ginseng has also been found to have an inhibitory effect on mouse skin tumors, which was proposed to be associated with its antioxidant activity. ${ }^{16}$

It is now recognized that ROS may play major roles in tumor promotion and progression, chronic diseases, and aging. ${ }^{5}$ The use of natural antioxidants as a potential preventive for free-radical mediated diseases has become a very important issue for improving the quality of life. This study demonstrates the significant antioxidant activity of plant extracts from $C$. formosana, especially the heartwood extract. This may indicate that the plant extracts or the derived phytocompounds from $C$. formosana have a great potential cancer chemopreventive effects or efficacies on other radical-mediated diseases. More systematic studies on phytochemistry as well as the in vitro and in vivo biofunction assays of $C$. formosana are currently in progress.

Acknowledgments This study was supported by a grant (NSC-912313-B-002-380) from the National Science Council of the Republic of China. The authors thank the National Science Council for this support and Mr. Tso-Yuan Hsieh (The Experimental Forest of National Taiwan University) for providing Calocedrus formosana materials.

\section{References}

1. Finkel T, Holbrook NJ (2000) Oxidants, oxidative stress and the biology of aging. Nature 408:239-247

2. Pietta PG (2000) Flavonoids as antioxidants. J Nat Prod 63:1035-1042

3. Cerutti PA (1994) Oxy-radicals and cancer. Lancet 344:862-863

4. Frei B (1995) Cardiovascular disease and nutrient antioxidants: role of low-density lipoprotein oxidation. Crit Rev Food Sci Nutr 35:83-98

5. Shireiqi I, Reddy P, Brenner DE (2000) Chemoperevention: general perspective. Crit Rev Oncol/Hematol 33:157-167

6. Lin YT, Lo TB, Lin TH (1956) Study of the extractives constituents from the wood of Libocedrus formosana Florin. II. Interconversion between isoshonanic acid and thujic acid. J Chin Chem Soc 3:36-40

7. Lo TB, Lin YT (1956) Study of the extractives constituents from the wood of Libocedrus formosana Florin. I. J Chin Chem Soc 3:30-35
8. Cheng YS, Lo TB, Chang LH, Lin YT (1961) Study of the extractives constituents from the wood of Libocedrus formosana Florin. IV. Partial hydrogenation of thujic acid. J Chin Chem Soc 8:103-108

9. Fang JM, Jan ST, Cheng YS (1985) (+)-Calocedrin, a lignan dihydroanhydride from Calocedrus formosana. Phytochemistry 24:1863-1864

10. Fang JM, Jan ST, Cheng YS (1987) Terpenoids from Calocedrus formosana. Phytochemistry 26:853-854

11. Chang ST, Wang SY, Wu CL (2000) Identification of exudates from the bark of Calocedrus formosana (Florin) Florin (in Chinese). For Prod Ind 9:59-66

12. Wang SY, Wu JH, Shyur LF, Kuo YH, Chang ST (2002) Antioxidant activity of abietane-type diterpenes from heartwood of Taiwania cryptomerioides Hayata. Holzforschung 56:487492

13. Pietta P, Simonetti P, Mauri P (1998) Antioxidant activity of selected medicinal plants. J Agric Food Chem 46:4487-4490

14. Gyamfi MA, Yonamine M, Aniya Y (1999) Free-radical scavenging action of medicinal herbs from Ghana Thonningia sanguinea on experimentally-induced liver injuries. Gen Pharmacol 32:661667

15. Kirby AJ, Schmidt RJ (1997) The antioxidant activity of Chinese herbs for eczema and of placebo herbs-1. J Ethnopharmacol 56:103-108

16. Keum YS, Park KK, Lee JM, Chun KS, Park JH, Lee SK, Kwon H, Surh YJ (2000) Antioxidant and anti-tumor promoting activities of the methanol extract of heat-processed ginseng. Cancer Lett 150:41-48

17. Kujala TS, Loponen JM, Klika KD, Pihlaja K (2000) Phenolics and betacyanins in red beetroot (Beta vulgaris) root: distribution and effect of cold storage on the content of total phenolics and three individual compounds. J Agric Food Chem 48:5338-5342

18. Halliwell B (1999) Food-derived antioxidants. Evaluating their importance in food and in vivo. Food Sci Agric Chem 1:67-109

19. Zi X, Mukhtar H, Agarwal R (1997) Novel cancer chemopreventive effects of a flavonoid antioxidant silymarin: inhibition of mRNA expression of an endogenous tumor promorter TNF $\alpha$. Biochem Biophys Res Commun 239:334-339

20. Ohsugi M, Fan W, Hase K, Xiong Q, Tezuka Y, Komatsu K, Namba T, Saitoh T, Tazawa K, Kadota S (1999) Active-oxygen scavenging activity of traditional nourishing-tonic herbal medicines and active constituents of Rhodiola sacra. J Ethnopharmacol 67:111-119

21. Liu F, Ng TB (2000) Antioxidative and free radical scavenging activities of selected medicinal herbs. Life Sci 66:725-735

22. Hu C, Kitts DD (2000) Studies on the antioxidant activity of Echinacea root extract. J Agric Food Chem 48:1466-1472

23. Sato M, Ramarathnam N, Suzuki Y, Ohkubo T, Takeuchi M, Ochi H (1996) Varietal differences in the phenolic content and superoxide radical scavenging potential of wines from different sources. J Agric Food Chem 44:37-41

24. Lavelli V, Peri C, Rizzolo A (2000) Antioxidant activity of tomato products as studied by model reactions using xanthine oxidase, myeloperoxidase, and copper-induced lipid peroxidation. J Agric Food Chem 48:1442-1448

The publication of this article was made possible by an Emachu Research Fund. The authors are greatful for the fund. 